\title{
Miscellany
}

\section{Psychiatrists at war}

Channel Four Television is making a major series on the history of military psychiatry. from the First World War to today. They would like to speak to psychiatrists who have worked for the Armed Forces, seen active service in a conflict overseas, or worked in a military psychiatric hospital in the UK. They are keen to speak to relatives, or former students of leading psychiatrists of the day. They are also interested in speaking to anyone researching this area, or anyone who has relevant photographs or archive material. Please telephone Rob, Sally or Julia on 01817483113.

\section{Partnership formed to review health of NHS workforce}

The problem of poor health and high stress levels among the NHS workforce and the failure of the NHS to improve working conditions are causing such concern that a unique partnership has been convened to promote remedial action. Work is just starting on a major review of the health of the NHS workforce and the report will be launched in March 1998. Under the auspices of The Nuffield Trust, the Partnership of the Health of the NHS Workforce comprises representatives of the British Association of Medical Managers, British Medical Association, Department of Health, Faculty of Occupational Medicine, General Medical
Council, Institute of Health Service Managers, National Counselling Service for Sick Doctors, NHS Confederation, Royal College of Psychiatrists and UNISON. The Convenor of the Partnership is Mr John Owen, Secretary of the Nuffield Trust. The review examines all categories of health care professionals and the value of the Partnership is that its members are well placed to reach all those in a position to achieve improvements in staff health. Further information: Cherry Chapel at the Nuffield Trust, 59 New Cavendish Street, London W1M 7RD (Tel: 0171 351 7545).

\section{Survey reveals more positive attitudes to schizophrenia among the Great Britain public}

A MORI survey of the general public, recently published, reveals a shift to more positive attitudes about schizophrenia, with people recognising it as a treatable mental illness and supporting community care. Just over $72 \%$ of the 1804 adults taking part in the MORI survey considered that, with careful support and appropriate treatment, people with schizophrenia can live successfully in the community. The most encouraging finding is the high level of support for care of the mentally ill in the community, as long as it is properly funded. Further information: Alison Spink or Mei Go on 01713069000. 